\title{
MUSCLE FIBRES IN CHILDREN'S STOOLS
}

\author{
BY \\ JOHN L. EMERY \\ From the Department of Pathology, The Children's Hospital, Sheffield
}

(RECEIVED FOR PUBLICATION NOVEMBER 3, 1952)

The examination of stools for the presence of undigested fragments of muscle seems to be a reasonable approach to studies of defective digestion. Procedures such as Schmidt's breakfast were at one time familiar clinical practice, but now such methods are rarely considered. This is not surprising, as the literature contains generalizations and indefinite statements; for example, 'The undue presence of meat fibres after a test meal indicated a fault in small intestine activity' (Gradwohl, 1948). Behrendt (1949) summarizes the situation thus:

'It is not yet certain whether the presence of a considerable number of undigested muscle fibres in the stools of children with chronic nutritional disturbances is indicative of diminished pancreatic function. Food may move so rapidly to the small intestine in many of these patients that the presence of muscle fibres may be the result of mechanical factors rather than digestive enzymic failure.'

Payne (1952) considers that muscle fibres in children's stools are only of significance if found in large numbers, whereas Lagercrantz (1949) in discussing stools in ulcerative colitis considers the presence of muscle fibres to be signs of poor digestion. Harrison (1947) when discussing tests of pancreatic function considers the examination of stools for muscle fibres as 'simple and valuable'.

In the course of a general survey of children's stools carried out in Sheffield all stools were examined for the presence of muscle fibres. An attempt is made here to determine the incidence of muscle fibres in stools and their relationship to other conditions in these children.

\section{Material and Methods}

The material used for this study consisted of just over 1,000 specimens of stools from children of varying ages. The material was identical with that already presented in a study of the normal range of tryptic activity in stools (Emery, 1952). As wide a range of children as possible was obtained, the aim being to secure specimens from a type of child in which a request for the examination of stool would be unlikely. No examinations requested by clinicians were incorporated.

The children received a normal diet, the source of meat in most instances being mincemeat with gravy for lunch. Meat was not given in large amounts.

Three slide preparations were made from each specimen. A small fragment of stool was broken down with saline and then set up with (1) Sudan IV, (2) saturated copper nitrate (Harrison, 1947) and (3) Lugol's iodine. The density of the preparations was gauged so that as far as possible the suspension seen through the microscope filled the field uniformly and without superimposition of faecal masses.

The fibres were only recognized if they showed striations as well as the longitudinal form of muscle fibres. The stool was considered positive $(+)$ if muscle fibres were found in at least two of the three preparations. Muscle fibres were considered to be present in large numbers $(++)$ when a large number of muscle fibres were present in all preparations, there being many muscle fibres in every high power field examined, and fibres with ragged ends, the picture conforming to what Harrison describes as true 'creatorrhea'.

An attempt was made to give children fragments of uncooked meat in small muslin bags and later to collect the bags from the stools and examine the contents. This was abandoned because of the disturbance when swallowing the bags - even when hidden in sandwiches or jam.

\section{Results}

Muscle Fibres Related to Age. Naturally no muscle fibres were found in unweaned children's stools. In weaned children between the ages of 6 months and 1 year, 97 specimens were examined of which two only contained many muscle fibres and in $66\left(69^{\circ}\right)$ none were found. In this age group, 13 months to 2 years inclusive, of 208 examinations, $68\left(33^{\circ}{ }_{\mathrm{o}}\right)$ were negative, $117\left(56^{\circ}{ }_{\mathrm{o}}\right)$ were positive and $23\left(11^{\circ}\right)$ contained fibres in large numbers. In the next two years, $44\left(27^{\circ}\right)$ of 163 had no fibres, while in children of 5 years and older $118\left(24 \cdot 5^{\circ}{ }_{0}\right)$ of 481 examined were negative and $30\left(6 \cdot 5^{\circ}{ }_{o}\right)$ were strongly positive. The incidence of muscle fibres does not appear to be significantly affected by age.

Muscle fibres were present in between $67^{\circ}$ o and $75^{\circ}$ of all stools passed in all age groups over a year and in very large numbers in $10^{\circ}$ o in younger children and $6_{\%}^{\circ}$ in older children. 
Muscle Fibres Related to Weight, Height and Nutrition. Seven hundred and eighty-nine specimens were examined from children considered to be of normal weight and 142 from children considered to be under weight. In the normal children muscle fibres were present in $517\left(70^{\circ}{ }_{0}\right)$ of specimens and in large numbers in $50\left(7^{\circ}\right)$, whereas in the underweight children fibres were found in $76\left(54^{\circ}{ }_{0}\right)$ and in large numbers in four $\left(3^{\circ} \%\right)$.

Thirty-eight specimens came from children described as being of abnormally small stature and the incidence of fibres in stools (13 negative, $24+$, 1 - -) showed no significant changes from the children of normal height.

Clinically wasted children accounted for 165 stools, and of these $83\left(50^{\circ} \%\right)$ showed no fibres and seven $(4 \%)$ showed fibres in large numbers. This compared with 797 stools from children of normal nutrition in which $249^{-}\left(31^{\circ} \%\right)$ showed no fibres and $48\left(6^{\circ}{ }_{0}\right)$ fibres in large numbers.

Oedematous patients accounted for 38 stools in which no abnormal incidence of muscle fibres was found.

There appears to be no significant difference in the incidence of muscle fibres in children of differing weights, heights, or general nutritional state.

Disease Groups Related to Presence of Muscle Fibres. Patients were divided into clinical groups (Table 1) depending on the system in which major symptoms presented. In the intestinal groups cases of fibrocystic disease of the pancreas were excluded and the group consisted chiefly of surgical patients.

TABLE 1

DISEASE GROUPS RELATED TO THE PRESENCE OF MUSCLE FIBRES

\begin{tabular}{|c|c|c|c|c|c|}
\hline Disease Group & & & Muscle & Fibres & \\
\hline & & Nil & + & $-T$ & Total \\
\hline Intestinal & & $45(47 \%)$ & $46(47 \%$ & $6(6 \%)$ & 97 \\
\hline Respiratory .. & . & $82(36 \%)$ & $135(60 \%$ & $11(4 \cdot 8 \%$ & 228 \\
\hline Cardiovascular & $\cdots$ & $41(22 \%$ & $127(69 \%$ & $17(9 \%$ & 185 \\
\hline Nephritic & . & $13(26 \%$ & $31(63 \%)$ & $5(10 \%$ & 49 \\
\hline Others & . & $162(39 \%$ & $236(57 \%$ & $19(4.6 \%)$ & 417 \\
\hline 'Healthy' & . & $34(31 \%$ & $75(67 \%)$ & $2(2 \%)$ & 111 \\
\hline
\end{tabular}

The majority of the cardiovascular patients were children with acute rheumatism or congenital deformity of the heart. The 'healthy' children were either the children of colleagues and friends or children admitted to hospital for minor anatomical deformities, such as operation for hernia. It was interesting to see that the incidence of stools free of muscle fibres was higher in the intestinal group $\left(47^{\circ}{ }_{0}\right)$ than in any other groups or in the apparently healthy children $\left(31_{\%}^{\circ}\right)$. However, there appears to be no difference of any significance between the groups of children and the incidence of muscle fibres in stools.

Muscle Fibres Related to Intestinal Passage Time. Using colour markers the intestinal passage time was obtained in 177 specimens. Seventeen of 18 stools passed within 10 hours contained muscle fibres, but 29 of 35 stools passed after 20 and before 30 hours similarly contained fibres (Table 2 ).

TABLE 2

MUSCLE FIBRES IN STOOLS RELATED TO INTESTINAL PASSAGE TIME

\begin{tabular}{|c|c|c|c|c|c|c|}
\hline \multirow[b]{2}{*}{ Intestinal Passage } & \multirow[b]{2}{*}{ Time } & & \multicolumn{4}{|c|}{ Muscle Fibres } \\
\hline & & & Nil & $\div$ & $-\div$ & Total \\
\hline $\begin{array}{l}10 \text { hours and less } \\
11 \text { to } 20 \text { hours } \\
21 \text { to } 30 \text { hours } \\
31 \text { hours or more }\end{array}$ & $\begin{array}{l}\ldots \\
\cdots \\
\cdots\end{array}$ & $\begin{array}{l}\cdots \\
\cdots \\
\cdots\end{array}$ & $\begin{array}{r}1 \\
9 \\
3 \\
13\end{array}$ & $\begin{array}{l}17 \\
41 \\
29 \\
52\end{array}$ & $\begin{array}{l}0 \\
2 \\
3 \\
7\end{array}$ & $\begin{array}{l}18 \\
52 \\
35 \\
72\end{array}$ \\
\hline
\end{tabular}

When the incidence of muscle-free stools passed before 20 hours (10 of 70 ) and those 20 hours and later (16 of 107) was compared no significant differences were found. It appears that the elimination of muscle fibres is not directly related to the length of time the fibres are in the intestinal tract.

Muscle Fibres Rebated to Tryptic Activity of the Stook. Both tryptic activity and muscle fibres were recorded on 999 specimens. In 341 no muscle fibres were found, and, of these, 17 stools showed no tryptic activity while 240 showed activity at a dilution of 1 in 100 or more.

When groups of specimens containing tryptic activity in a dilution of 1 in 10 or less and those with tryptic activity at a dilution of more than 1 in 100 were compared, it was found that $37 \%$ (70 of 191) of the low tryptic activity group showed no muscle fibres while $33 \%$ (240 of 727 ) of the high tryptic activity group gave a similar result. Thus it would seem that the absence of muscle fibres in stools is not directly related to the tryptic activity of the stools. When, however, the incidence of a large number of muscle fibres was similarly compared, it was found that in the group of 191 with low or absent tryptic activity $22(11 \cdot 6 \%)$ had gross fibres, while of the 727 with high tryptic activity the number was 35 $(4 \cdot 8 \%)$. These figures show a significant difference and suggest a greater incidence of gross muscle remnants in stools with a low or absent tryptic activity.

Muscle Fibres Rebated to Undigested Starch in Stooks. The presence of muscle fibres and starch granules was investigated in 1,000 stools. The starch granules were recorded as being either absent, 
present intracellularly, or present both extracellularly and intracellularly.

When the stools containing no starch granules and those with extracellular granules were considered together with the stools containing no muscle fibres and those with very large numbers of fibres, there appeared to be a relationship between the incidence of a large number of muscle fibres and the presence of extracellular starch.

Of 295 specimens containing no muscle fibres 213 $\left(72^{\circ}{ }_{0}\right)$ showed no starch granules and $82\left(28^{\circ}{ }_{0}\right)$ extra cellular granules. Of 45 specimens with much muscle remnant $10\left(22^{\circ}{ }_{o}\right)$ showed no starch and $35\left(78^{\circ}{ }_{o}\right)$ extracellular starch.

\section{Discussion}

The principal difficulty in a survey of the present type is that the estimation of the amount of creatorrhea present is subjective. In this study an attempt was made to include in the - category numbers of muscle fibres that would normally be considered of no clinical importance, and to reserve for the - - category amounts that on criteria indicated by Harrison (1947) would certainly be considered as being of pathological significance.

The children used in this survey excluded children in whom the diagnosis of fibrocystic disease of the pancreas or coeliac disease could be clinically suggested. When, however, stools from known cases of fibrocystic disease are examined muscle fibres are usually seen but in no greater number than those in the - - category described in this survey.

It was found that on microscopy muscle fibres are present in between two-thirds and three-quarters of stools passed by children of all ages. The presence of the muscle fibres was apparently independent of the nutritional state of the child, and of any particular disease group or notable disease. This figure agrees with the general statements made that muscle fibres in small numbers may be considered to be usual constituents of children's stools. When muscle fibres in large numbers were considered alone the incidence fell to between $5^{\circ}{ }_{0}$ and $10^{\circ}{ }_{o}$ of stools but still showed no apparent relationship between nutritional state, age, or disease group.

From a purely clinical and diagnostic viewpoint, that of defect in digestion or pancreatic disease, it seems that the laboratory examination of stools for muscle fibres is a pointless procedure.

The observation that the presence of undigested muscle fibres is related both to the presence of extra:cellular starch granules and to the lower limits of tryptic activity of the stool suggests that the presence of the muscle fibres in large numbers is not completely fortuitous, in that it appears to be related to other changes in the stools.

No comparable figures appear to be available to say whether or not the creatorrhea found in the children in Sheffield is universal or only of recent origin. It is, of course, possible that the normal digestive economy of the child permits the elimination of undigested food but two other possibilities seem more likely. First, there is anatomical evidence (Andersen, 1938; Blackfan and May, 1938; Emery, 1951 ) to suggest that minimal degrees of pancreatic disease occur in a sub-clinical and probable reversible form, and second, which may be directly related to the previous point, that our knowledge of diet is inadequate and the diet may contain substances interfering with muscle digestion as glutens (Anderson, Fraser, French, Gerrard, Sammons and Smellie, 1952) interfere with starch. Mellanby (1951) recently pointed out the extent of commercial food contamination with substances of unknown physiological effect. It is believed by many that acrodynia is produced by mercury intoxication from teething powders (Warkany and Hubbard, 1948), and it is possible that mercury is not the only substance that may be harmful and is given unwittingly to children.

In this study we have seen an aspect of digestion which we cannot say is physiological or pathological and it would appear to be as well to keep an open mind on this point until further evidence is obtained.

\section{Summary}

A survey was made of 1,000 stools from children showing no clinical features suggesting fibrocystic disease of the pancreas.

Muscle fibres were present in the stools of children in between two-thirds and three-quarters of stools passed. Muscle fibres in what would be considered pathological numbers were also present in between $5^{\circ}{ }_{o}$ and $10^{\circ}{ }_{0}$ of stools from similar children.

The creatorrhea appeared to be completely unrelated to age, nutritional state, disease groups, or intestinal passage time of food.

A relationship was found between the presence of many muscle fibres in stools and the presence of extracellular starch granules and reduced tryptic activity.

It is not known whether creatorrhea is physiological or pathological in children, but from a clinical viewpoint microscopic examination of the stools for muscle fibres appears to be a useless procedure.

It is a pleasure to acknowledge the help of the nursing staff at the Children's Hospital, Nether Edge Hospital, the Jessop Hospital, King Edward Orthopaedic Hospital, 
Ash House Hospital School, the Moss Residential Nursery, and many other individuals for their assistance in collecting specimens of stool.

\section{REFERENCES}

Anderson, C. M., Frazer, A. C., French, J. M., Gerrard. J. W., Sammons, H. G. and Smellie, J. M. (1952). Lancet, 1, 836.

Andersen, D. H. (1938). Amer. J. Dis. Child., 56, 344.

Behrendt, H. (1949). In Diagnostic Tests for Infants and Children, p. 21. New York
Blackfan, K. D. and May, C. D. (1938). J. Pediat., 13. 627.

Emery, J. L. (1951). Archives of Disease in Childhood, 26, 570 - (1952). Ibid., 27, 257.

Gradwohl, R. B. H. (1948). Clinical Laboratory Methods and Diagmosis, 4th ed., vol. I, p. 1118 . London.

Harrison, G. A. (1947). Chemical Methods in Clinical Medicine, 3rd ed., p. 264. London.

Lagercrantz, R. (1949). Acta paediat., Uppsala, Suppl., 75, 89.

Mellanby, E. (1951). Brit. med. J., $2,863$.

Payne, W. W. (1952). J. Gt Ormond Street Hospital, no. 3, p. 23

Warkany, J. and Hubbard, D. M. (1948). Lancet, 1, 829. 